\title{
Load and settlement of pile-raft foundation at post consolidation from 3D FEM analysis
}

\author{
Der-Wen Chang ${ }^{\text {i) }}$, Wei-Chen Lin ${ }^{\text {ii) }}$ and Chih-Wei Lu ${ }^{\text {iii) }}$
}

\begin{abstract}
i)Professor, Department of Civil Engineering, Tamkang University, New Taipei City 251, Taiwan, ii) Research Assistant, Department of Civil Engineering, Tamkang University, New Taipei City 251, Taiwan. iii) Associate Professor, Department of Construction Engineering, NFUST, Kaohsiung City 824, Taiwan.
\end{abstract}

\begin{abstract}
Load and settlement behaviors of a numerical pile-raft foundation in soft soils after the consolidation are presented in this paper. Modified Cam Clay (MCC) model was adopted to model the soil behaviors. Three dimensional FEM analysis based on MIDAS-GTS program was conducted in the study. The influences of pile-to pile spacing distance and pile length as well as soil model parameters were monitored. It generally finds that the trend of the load distribution and settlements of piles and raft are dependent of these effects. A post consolidation analysis for a pile-raft foundation under the loads could be suggested for the long-term condition of the foundation.
\end{abstract}

Keywords: pile-raft foundation, load, settlement, 3D FEM analysis

\section{INTRODUCTION}

Seismic performance of the pile-raft foundation is receiving considerable attentions from geotechnical engineers in Taiwan. In recent years, a numerical model of the bridge pile foundations located in Taipei has been studied by the authors using Performance Based Earthquake Engineering (PBEE) analysis (Kramer, 2008) and Monte Carlo Simulations. It was found both approaches on probability method and reliability method could provide agreeable assessments for the seismic performance of the piles. Fig. 1 illustrates the results of PBEE analysis, and Table 1 reveals the factors of safety for seismic performance of the pile, computed from both approaches.

Fig. 1 indicates that using the moment capacities of the pile, one can find the corresponding pile displacements allowed at the same levels of annual rate of exceedance associated with both the moments and the displacements. More details can be found in Chang and Lee (2013), Chang et al. (2014 $\left.{ }^{\mathrm{b}}\right)$.

The results were obtained using a simplified analysis called EQWEAP (Chang et al., 2014 ${ }^{\mathrm{a}}$ ). It was suggested that this type of solution can be used to predict pile deformational behaviors for the bridge pile foundation with finite cap dimensions. For large size pile-raft foundation, the application of such analysis needs to be verified. Solution from a three dimensional finite element (FE) analysis is considered for the comparisons and validations.
Table 1. Factor of safety for seismic performance of numerically modeled piles (after Chang et al, 2014 ${ }^{\mathrm{b}}$ )

\begin{tabular}{cccc}
\hline \multirow{2}{*}{ Method } & \multicolumn{3}{c}{ Factor of safety, $\mathrm{FS}_{\mathrm{P}}$ and $\mathrm{FS}_{\mathrm{R}}$} \\
\cline { 2 - 4 } & Moderate EQ & Design EQ & MCE quakes \\
\hline PBEE & 0.702 & 1.133 & 1.113 \\
\hline MCS & 0.696 & 2.17 & 2.17 \\
\hline
\end{tabular}

In order to know static foundation behaviors better prior to the dynamic ones. A pilot study was carried by 3D FE analysis on numerical models of the foundation. General design guideline of the pile-raft foundation can be found in Katzenbach and Choudhury (2013), it is interesting to conduct further studies in this regard. This paper intends to discuss the load-deformational behaviors of pile-raft foundations in soft clays using three-dimensional finite element analyses based on Midas-GTS program (MIDAS, 2009). A simple numerical model of a presumed pile-raft foundation consisting of a $27 \mathrm{~m} \times 23 \mathrm{~m} \times 1.5 \mathrm{~m} \quad(\mathrm{~L} \times \mathrm{B} \times \mathrm{H}) \quad$ raft underlain by a number of piles with diameter of one meter was considered. The foundation is made of concrete. Homogeneous soil layer of clay was assumed on top of the rigid rock. 3D solid elements were selected to model both foundation and soil. Notice that with this type of modeling, each node of the structure can only exert vertical and horizontal displacements. The flexural deformations of the structure can be seen if the discretization of the structure preserved the efficiency. In any case if the bending moments of the raft and the piles were preferred, one can further computed them with the resolved structural displacements and proper material laws. Iterative scheme should be adopted if any nonlinearity was 
involved in the computations. With the use of Modified Cam Clay (MCC) model for the soils, the foundation behaviors were examined. For simplicity, post-consolidation type of analysis was employed. Therefore, this study only reveals the results for pile-raft foundations at the final stage of long-term condition. The influences of pile-to-pile spacing distance (S), pile length (1), and soil model parameters were investigated. Friction piles and end bearing piles were also simulated to see their differences. Uniform vertical and horizontal loads as well as bending moment were applied respectively onto the foundation for the investigations.
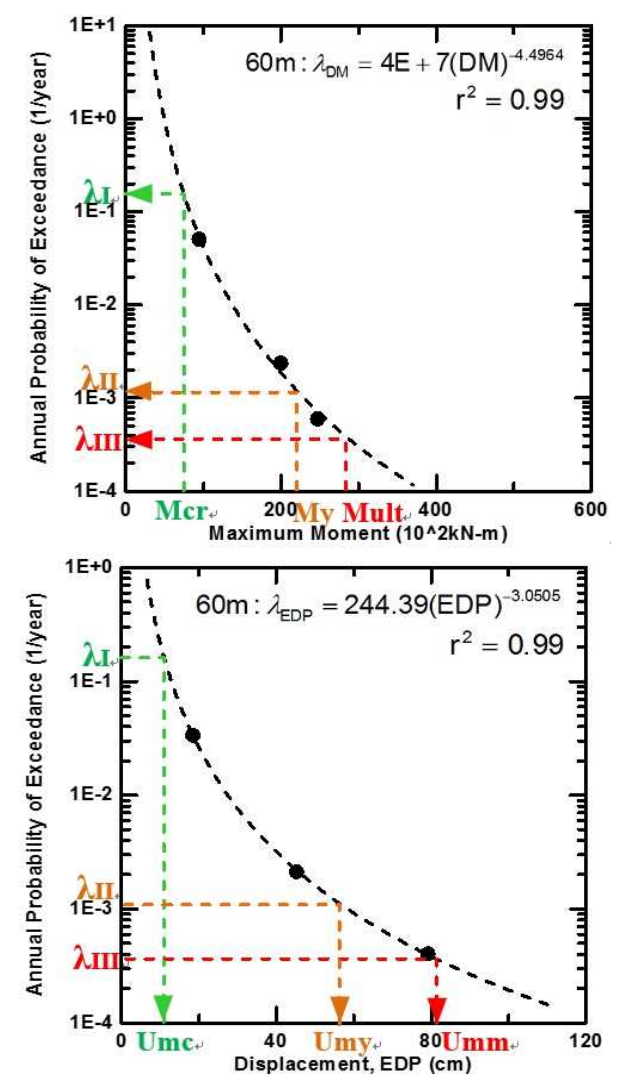

Fig. 1. Annual rate of exceedance for the maximum displacement and bending moment of single piles (from Chang et al., 2013).

\section{NUMERICAL MODELING}

The stability and convergence of the numerical solution were verified changing the size of the finite element core. As the result, an area of $100 \mathrm{~m} \times 100 \mathrm{~m} \mathrm{FE}$ core was decided. The thickness of homogeneous soft clayey layer was kept as $40 \mathrm{~m}$ to reduce the required computational time. Essential boundary conditions were adopted. Dimensions of the structure and material parameters of the foundation and soil are shown in Table 2. Ground water table is kept at $6 \mathrm{~m}$ below the ground surface. Since the long-term load-settlement relation of the foundation is preferred, the analysis was carried out assuming that the soils had been fully consolidated. Thus normally consolidated soil was considered. Total loads were applied simultaneously onto the foundation located in such ground.

Table 2. Structural dimensions and parameters of MCC model

\begin{tabular}{ll|l}
\hline Structural dimensions & \multicolumn{1}{l}{} \\
\hline Pile diameter & & $1 \mathrm{~m}$ \\
\hline Pile length & \multicolumn{2}{l}{$10,20,30 \mathrm{~m}$} \\
\hline MCC soil model parameters & $\gamma$ & $18 \mathrm{kN} / \mathrm{m}^{3}$ \\
\hline Soil unit weight & $\gamma_{\text {sat }}$ & $20 \mathrm{kN} / \mathrm{m}^{3}$ \\
\hline Soil unit weight (saturated) & $v$ & 0.3 \\
\hline Poisson's ratio & OCR & 1 \\
\hline Over Consolidation Ratio & $\lambda$ & 0.152 \\
\hline Slope of Normal Consol. Line & $\lambda$ & 0.0152 \\
\hline Slope of Over Consol. Line & $\pi$ & 3.8 \\
\hline Critical State Specific Vol. & $\mathbb{T}$ & 1 \\
\hline Initial Void Ratio & $\varphi_{0}$ & 1.157 \\
\hline Slope of Critical State Line & $\mathrm{M}$ & 0.52 \\
\hline Lateral earth pressure & $k_{0}$ & 0.52 \\
\hline $\begin{array}{l}\text { Pre-consolidation effective } \\
\text { pressure }\end{array}$ & $p_{c}$ & $270 \mathrm{kN} / \mathrm{m}^{2}$ \\
\hline
\end{tabular}

This could be called as a post-consolidation analysis. Uniform vertical loads of $100 \mathrm{kPa}$ (similar to $10-\mathrm{fl}$ building load) and $15 \%$ of them for the horizontal loads were applied on top of the foundation, respectively. A bending moment of $186.3 \mathrm{MN}-\mathrm{m}$ was calculated with total horizontal load acting at $20 \mathrm{~m}$ height from top of the raft foundation. Note that the bending moment can be directly applied onto the raft since the $3 \mathrm{D}$ solid elements were used to model the structure. Three dimensional elements with wedge or hexahedron shapes were utilized to form the foundation and soil. A 3D FE model is illustrated in Fig. 2. The corresponding model solutions for foundations under vertical, horizontal loads and rocking motions are plotted in Fig. 3. It is important to point out that the interface (contact) elements were not adopted. Such decision indeed will cause a defect to the solutions especially for the stresses affected by the material interfaces.

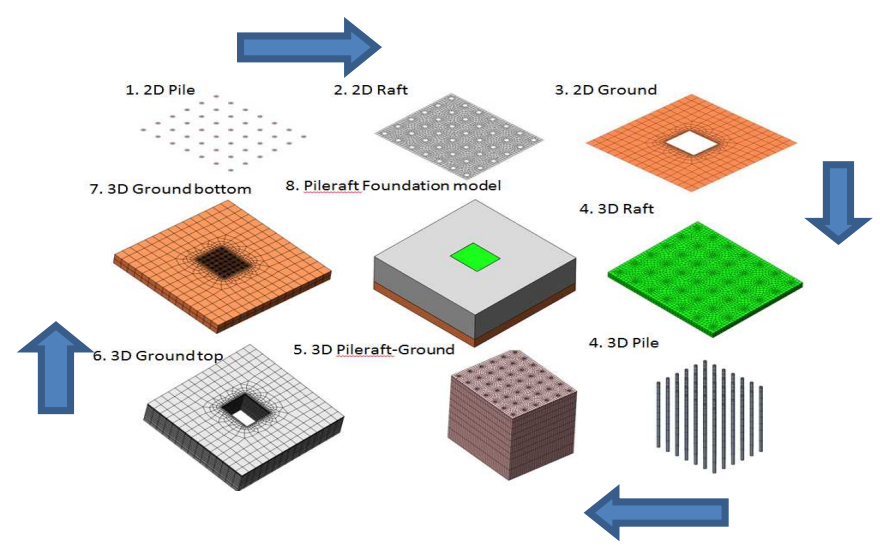

Fig. 2. Layout of the 3D FEM modeling. 


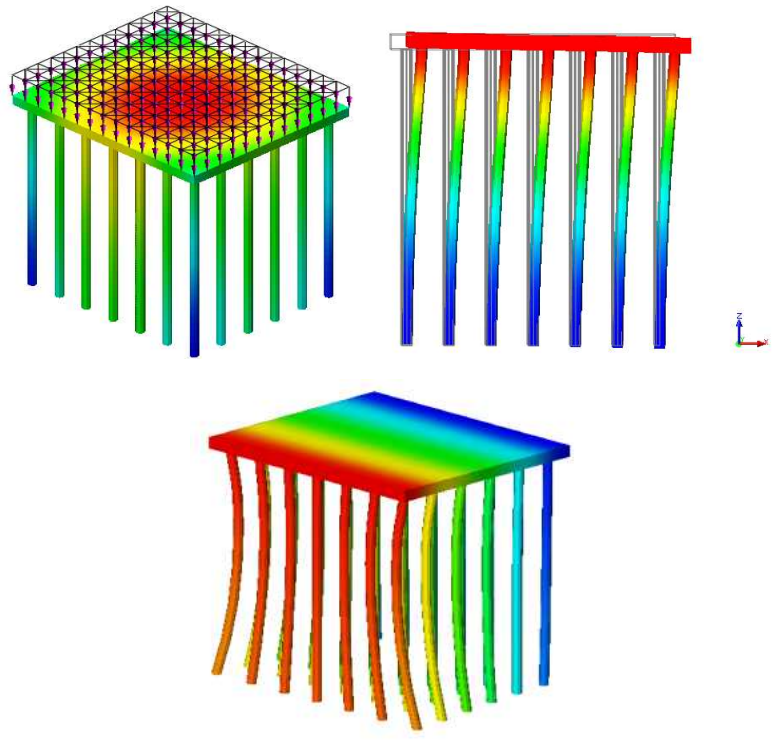

Fig. 3. 3D FEM solutions of the modeling.

\section{OBSERVATIONS ON SETTLEMENTS}

The displacements of the raft under the vertical loads are in a range of $3 \sim 4 \mathrm{~cm}$ as shown in Fig. 4. It can be clearly seen that the maximum displacement occurred at the center of raft and they are dependent of the ratio of pile-to-pile spacing distance and pile diameter $(\mathrm{S} / \mathrm{D})$. For less number of piles involved $(\mathrm{S} / \mathrm{D}=5)$, the maximum settlement will be increased. Of course, the settlements are strongly dependent of pile length. One can find that it is very clear the raft-pile foundation settle more and more as the number of piles decreases (pile spacing increased in this case). The whole foundation resistance is decreasing as the number of piles was decreased.

It is important to point out that the rigidity of the raft foundation is unlike the case of a cap in bridged pile foundation. The size of the raft foundation is much larger than the cap of a pile group foundation. The thickness of a raft is much less than the length and width of it. The rigidity for the raft foundation can be calculated, and mostly it was considered flexural rather than rigid, in which the foundation will settle differentially under large vertical loadings. Such phenomenon is thus improved by introducing the piles.

Fig. 5 shows the maximum settlements varying the pile length and compared to single raft foundation. The pile length is obviously very important in reducing the foundation settlements. Without the piles, the settlements of the raft could reach $10 \mathrm{~cm}$. Note that these settlements will increase with the thickness of the soil layer. For end bearing piles rest upon a rigid firm layer, the settlements were found only about $0.1 \sim 0.4 \mathrm{~cm}$, which is believed to be the elastic deformations of the pile-raft foundation. It was also observed that depth of ground water table, pre-consolidation pressure $\left(P_{c}\right)$, compression index $\left(\mathrm{C}_{\mathrm{c}}\right)$, recompression index $\left(\mathrm{C}_{\mathrm{s}}\right)$ and drained friction angle $\left(\phi^{\prime}\right)$ of the soil will also affect the settlements. Detailed discussions can be found in Lin (2014).

\section{OBSERVATIONS ON LOADS}

Corresponding load distributions of the raft and the piles is shown in Fig. 6. Note that the loads need to be computed by examining the corresponding stresses of the elements. It can be seen that the loads carried by the corner piles are larger than those of other piles. The load applied to the center pile(s) is the smallest. Similarly, the load distribution is also dependent of S/D and pile length. The associated ratios of the pile load and the total load, $\alpha_{v}$ are plotted in Fig. 7. In this study,

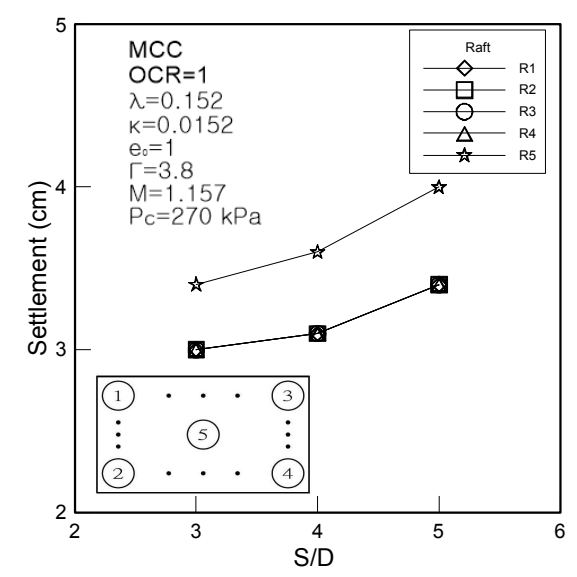

Fig. 4. Raft settlements affected by S/D.

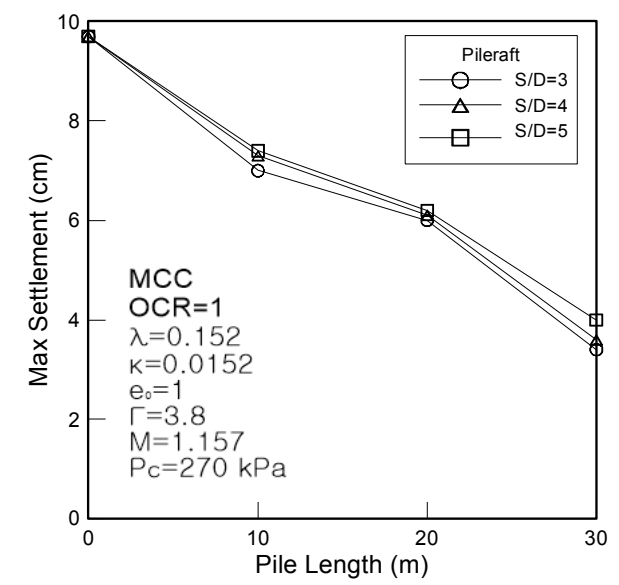

Fig. 5. Settlements affected by pile length.

they are between 0.6 and 0.8. As the pile length increases, the piles tend to carry more load acting on the foundation. However, the pile load will drop if the number of pile decreases. The frictional force along the pile is shown in Fig. 8. It is generally decreasing with the depth as it is expected for friction piles. However, at the bottom of the pile, the frictional force seems to increase again. Note that the piles are neither fixed at the bottom. This phenomenon is because that the compatibilities between soil and pile elements were 
used in the analysis. For better solution where friction would vanish at the bottom of the pile, contact element must be used. In that case, detach between soil and pile would not over-predict the frictions at bottom of the pile.

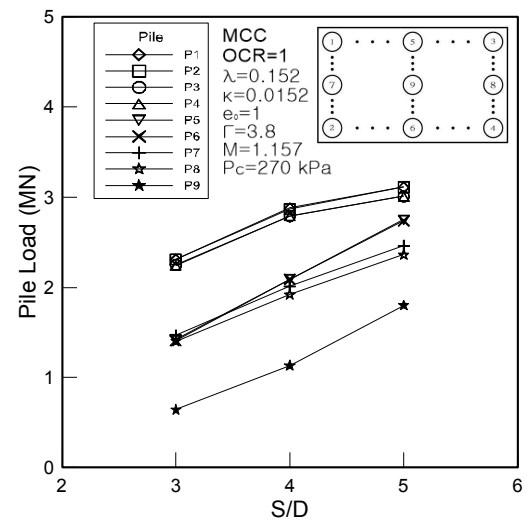

Fig. 6. Pile loads affected by S/D.

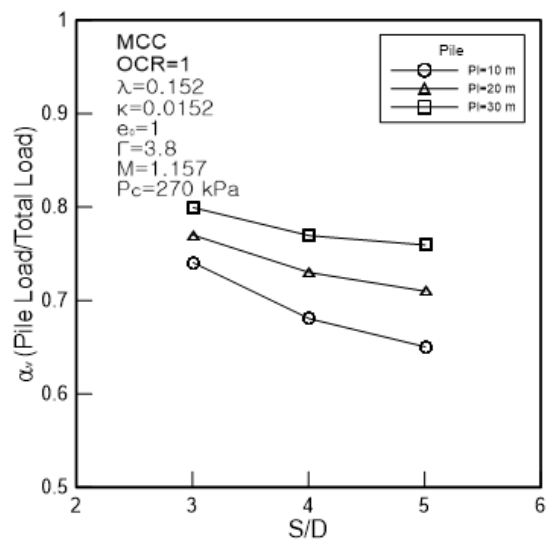

Fig. 7. Pile load ratios affected by S/D.

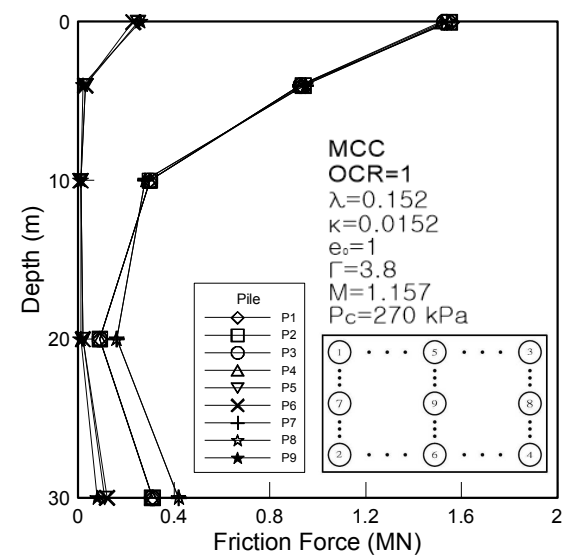

Fig. 8. Skin frictions along the piles.

\section{COMPARISONS OF THE MODELING}

A case study (see Fig. 9) presented by Katzenbach et al. (2007) was simulated using 3D MIDAS-GTS program. Soil model was kept the same as the Drucker-Prager model used originally. Comparable result of load-displacement curve can be shown in Fig.
10. The deviations become larger when the load and displacement increases. It is not very clear at this stage, however the numerical model especially the size of the analytical zone is believed to be the reason behind it.

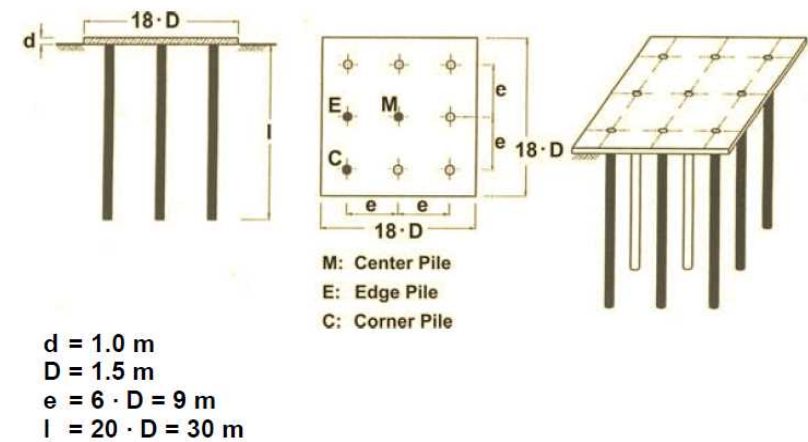

Fig. 9. Layout of the case study for comparative results (after Kazenbach et al., 2007).

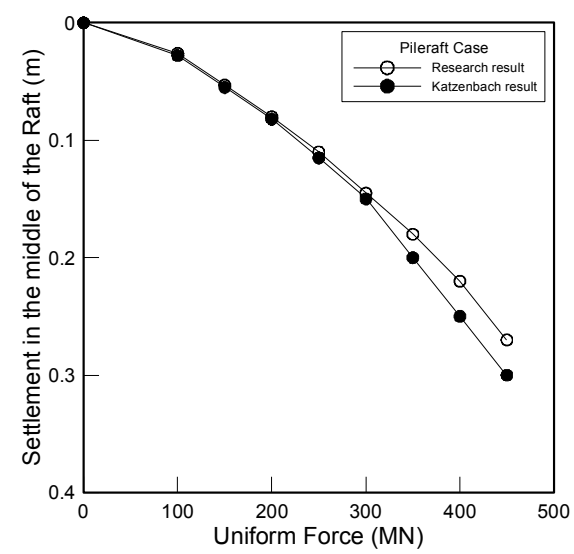

Fig. 10. Comparative load-settlement curves.

With the design charts suggested by Katzenbach et al. (1998) and Katzenbach and Choudhury (2013) in hand, the predictions for the load ratio, $\alpha$ and the settlement ratio of pile-raft foundation and single raft foundation, $\mathrm{S}_{\mathrm{pf}} / \mathrm{S}_{\mathrm{sf}}$ of the analysis on numerical pile-raft foundation in this study were plotted in Fig. 11 and Fig. 12. The results of this study are found compatible in Fig. 11. However, the corresponding values of $\mathrm{L} / \mathrm{D}$ suggested by this study, in which the settlement ratios and number of piles were determined and plotted in Fig. 12, are found much higher than the values suggested by Katzenbach (1998). This is believed to be caused by the soil model in use. The soil seems to be rather soft in this study than those used by Katzenbach. It should be noted that the post-consolidation analysis cannot reflect the long-term process of the load-settlement relationship with the time dependence. For time-dependent load-settlement curves such as those reported by Yamashita (2012), one should consider more rigorous modeling including the rheology of soil and its effects to the foundation behaviors. 


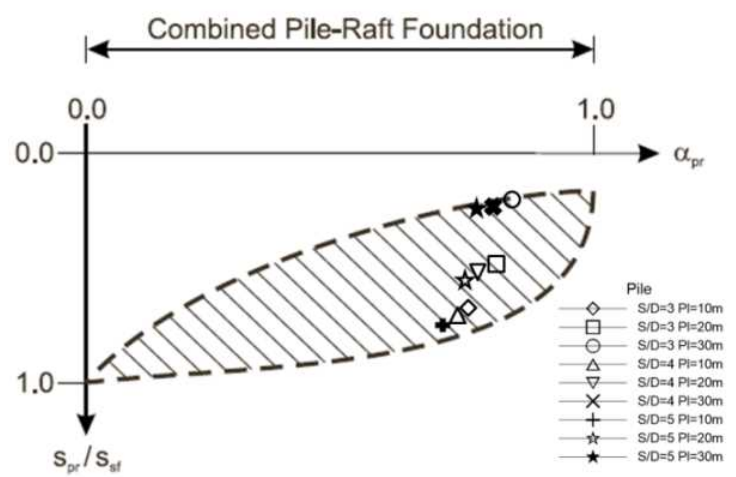

Fig. 11. Predictions of this study on load and settlement ratios (After Katzenbach and Choudhury, 2013).

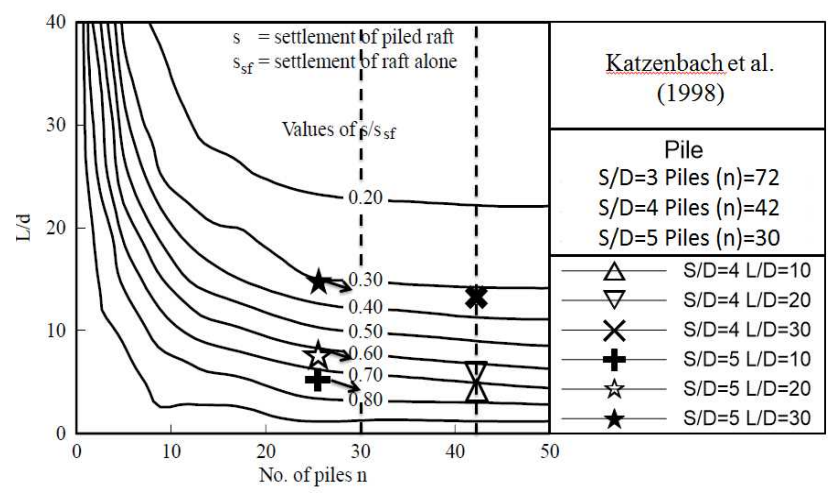

Fig. 12. Predictions of this study on load and settlement ratios (after Katzenbach, 1998).

\section{CONCLUDING REMARKS}

Under the uniform vertical loads, it is found that the largest foundation displacements of the numerical foundation model are on the order of $2 \sim 6 \mathrm{~cm}$, which occurred at the center of foundation. The foundation corner will exert smallest displacements. The loads transmitted to the corner piles are found larger than the edge piles and much larger than the center pile(s). Vertical loads carried by the numerical piles are found approximately $60 \% \sim 80 \%$ of the total load varying the ratios of $S / D$ in between 3-5 and $1 / B$ (where $D$ is kept as 1 meter) on the order of $0.43-1.3$. Frictions distributed along the piles will gradually decrease with the depth, and they are found much larger at the friction piles rather than those of the end bearing piles. The value of initial modulus of the soil is very sensitive to the results. For example, the foundation displacements resulted by using static material modulus suggested in many textbooks and/or correlated from undrained shear strength will be much higher than those obtained from dynamic modulus via wave velocity of the soil. For pile-raft foundations located in soft clay ground sites, the effects of soil consolidation should be carefully monitored. However, if the final long-term load-displacement behavior of the foundation is desired, one could use the post consolidation analysis to estimate the foundation behaviors, in which fully consolidated soils could be assumed.

\section{ACKNOWLEDGEMENTS}

This study presents the partial results of research funding from grant NSC102-2221-E-032-024-MY3 (original National Science Council) of Ministry of Science and Technology, Republic of China (Taiwan). The authors express their sincere gratitude towards the supports.

\section{REFERENCES}

1) Chang, D.W., Cheng, S.H. and Wang, Y.L. (2014 $\left.{ }^{\mathrm{a}}\right)$ : One-Dimensional Wave Equation Analyses for Pile Responses subjected to Seismic Horizontal Ground Motions, Soils and Foundations, 54(3) 313-328.

2) Chang, D.W. and Lee, S.M., (2013): Performance Based Design of Piles due Seismic Ground Motions, Procds., International Symposium on Safety of Foundation Engineering (ISAFE), Singapore, December 5-6.

3) Chang, D.W., Lin, Y.H., Chao, H.C., Chu, S.C. and Liu, C.H., $\left(2014^{\mathrm{b}}\right)$ : Seismic PBD on Piles from Monte-Carlo Simulation Using EQWEAP Analysis and Weighted Intensities, Geotechnical Engineering, 45(2) 62-69.

4) Katzenbach, R., Arslan, U., Moormann, C. and Reul, O. (1998): Pile Raft Foundation - Interaction Between Piles and Raft, Darmstadt Geotechnics, Darmstadt U. of Technology, no. 4, 279-296.

5) Katzenbach, R., Gutberlet., C. and Bachmann, G. (2007): Soil-Structure Interaction Aspects for Ultimate Limit State Design of Complex Foundations, ISGSR 2007, Proceedings, 1st Int. Symposium on Geotechnical Safety and Risk,Shanghai, Tongji U., China, 585-596.

6) Kazenbach, R. and Choudhury, D. (2013): ISSMGE Combined Pile-Raft Foundation Design Guideline, Technical U. Darmstadt, Institute and laboratory of Geotechnics.

7) Lin, W.C. (2014): Load and Deformation Behaviors of Pile-Raft Foundations from FEM Analysis, Master Thesis, Dept. of Civil Engr., Tamkang U., Taiwan.

8) MIDAS GTS (2009): Modeling, Integrated Design and Analysis Software User's Manual.

9) Yamashita, K. (2012): Field Measurement on Piled Raft Foundation in Japan, Proceedings of IS-Kanazawa, 79-96. 